\title{
Übersicht bisher erschienener Sonderhefte der Zeitschrift für Politikwissenschaft (ZPol)
}

() Springer Fachmedien Wiesbaden 2016

Strohmeier, Gerd (Hrsg.). 2009. Wahlsystemreform. Baden-Baden: Nomos.

Korte, Karl-Rudolf und Jan Treibel (Hrsg.). 2012. Wie entscheiden Parteien? Prozesse innerparteilicher Willensbildung in Deutschland. Baden-Baden: Nomos.

Bieber, Christoph und Sven Sebastian Grundmann (Hrsg.). 2013. Ethik und Politikmanagement. Baden-Baden: Nomos.

Kneuer, Marianne und Carlo Masala (Hrsg.). 2014. Solidarität. Politikwissenschaftliche Zugänge zu einem vielschichtigen Begriff. Baden-Baden: Nomos.

Jesse, Eckhard (Hrsg.). 2015. Wie gefährlich ist Extremismus? Gefahren durch Extremismus, Gefahren im Umgang mit Extremismus. Baden-Baden: Nomos.

Partzsch, Lena und Sabine Weiland (Hrsg.). 2015. Macht und Wandel in der Umweltpolitik. Baden-Baden: Nomos. 